\title{
A DIMENSÃO PEDAGÓGICA DO CINEMA NEGRO NA PERCEPCC̃̃O DO ETNOLETRAMENTO EM EDUCAÇÃ̃ BÁSICA
}

\author{
Celso Luiz Prudente $ه$
}

Agnaldo Périgo (1D $\triangle$ 
O objetivo deste artigo é questionar as formas curriculares tradicionais desenvolvidas nas escolas de Educação Básica, suscitando novas emergências epistemológicas. Analisaremos a dimensão pedagógica do Cinema Negro em contexto de etnoletramento. Isto será conjugado com as relações étnico-raciais, observando a emergência afirmativa da africanidade dos quilombolas. A região amazônica configura a existência de fenótipo ibero-ásio-afro-ameríndio enquanto maioria minorizada em relação ao euro-heteromacho-autoritário e o poder da euro-heteronormatividade. O etnoletramento refere-se ao aporte teórico da dimensão pedagógica do Cinema Negro e sobre como esses podem se tornar agentes de transformação social. Essas epistemologias dialogam dentro da construção de uma educação pautada na pedagogia crítica, objetivando uma mudança nos paradigmas educacionais, na prática pedagógica e na possibilidade dos relacionamentos étnico-raciais com diferentes epistemologias na Educação Básica. Há necessidade de compreender a especificidade quilombola na emergência do etnoletramento, bem como na dinâmica da dimensão pedagógica do Cinema Negro. Há, ainda, necessidade de novos estudos sociolinguísticos para uma educação emancipadora.

Palavras-chave: dimensão pedagógica do Cinema Negro;

\section{THE PEDAGOGICAL DIMENSION OF BLACK CINEMA IN THE PERCEPTION OF ETHNOLITERACY IN BASIC EDUCATION}

\section{ABSTRACT}

The objective of this paper is to question the traditional curricular forms developed in Basic Education schools, raising new epistemological emergencies. We will analyze the pedagogical dimension of Black Cinema in the context of ethnoliteracy. This will be combined with ethnic-racial relations, observing the affirmative emergence of the quilombola's Africanity. The Amazon region has in its population an IberoAsian-Afro-Amerindian phenotype as a minorized majority in relation to the Euro-hetero-male-authoritarian and the power of Euro-heteronormativity. Ethnoliteracy refers to the theoretical contribution of the pedagogical dimension of Black Cinema and how they can become agents of social transformation. These epistemologies dialogue within the construction of an education based on critical pedagogy, aiming at a change in educational paradigms, pedagogical practice, and the possibility of ethnic-racial relationships with different epistemologies in Basic Education. There is a need to understand the quilombola specificity in the emergence of ethnoliteracy, as well as in the dynamics of the pedagogical dimension of Black Cinema. There is also a need for new sociolinguistic studies for an emancipatory education.

Keywords: pedagogical dimension of Black Cinema; Ibero-Asian-Afro-Amerindian; Euro-hetero-male-authoritarian; ethnoliteracy; quilombola.

\section{LA DIMENSIÓN PEDAGÓGICA DEL CINE NEGRO EN LA PERCEPCIÓN DEL ETNOLETRAMIENTO EN LA EDUCACIÓN BÁSICA}

El objetivo de este artículo es cuestionar las formas curriculares tradicionales desarrolladas en las escuelas de Educación Básica, generando nuevas manifestaciones epistemológicas. Analizaremos la Dimensión Pedagógica del Cine Negro en el contexto del etnoletramiento. Esto se conjugará en las relaciones étnico-raciales, observando el surgimiento afirmativo de la africanidad de los quilombolas. La región amazónica compone un fenotipo ibero-asio-afro-amerindio que existe como una mayoría minorizada en relación con el euro-hetero-macho-autoritario y el poder de la euro-heteronormatividad. En el etnoletramiento se demuestra la contribución teórica de la Dimensión Pedagógica del Cine Negro y del etnoletramiento y cómo estos pueden convertirse en agentes de transformación social. Estas epistemologías dialogan en el interior de la construcción de una educación guiada por una pedagogía crítica, con el objetivo de que haya un cambio en los paradigmas educativos, en la práctica pedagógica y en la posibilidad de relaciones étnico-raciales con diferentes epistemologías en la Educación Básica. Existe la necesidad de comprender la especificidad quilombola en el surgimiento del etnoletramiento y en la dinámica de la Dimensión Pedagógica del Cine Negro. Se necesitan todavía nuevos estudios sociolingüísticos para una educación emancipadora.

Palabras clave: dimensión pedagógica del Cine Negro; Ibero-Asio-Afro-Amerindio; Euro-hetero-macho-autoritario; etnoletramiento; quilombola. 


\section{INTRODUÇÃO}

Ao longo de séculos, a educação vem experimentando mudanças em sua estrutura, nas políticas públicas e na forma como vem sendo vista e trabalhada no interior das escolas públicas de Educação Básica. Marco importante desses acontecimentos está vinculado à década de 60, embasado em diversos movimentos que teriam alavancado teorias com indagações ao pensamento e à estrutura educacional tradicional. Esses movimentos apontam uma prática de reconceptualização, ou seja, de se repensar sobre o currículo, a estrutura e a atividade pedagógica (Silva 2003).

A partir daí, surgem questionamentos sobre a educação tradicional, um modelo embasado apenas no suposto tecnicismo curricular, sem se preocupar como este seria trabalhado, elaborado e organizado. Trava-se, então, uma discussão sobre esse cenário, abrindo espaço ao debate para a população, que aceita este movimento, pois entende a possibilidade deste questionamento atuar como viés de transformação em favor de sua especificidade (Silva 2003).

Ao se pensar, hoje, em educação, práticas pedagógicas e diversidade, é impossível separar tais contextos. Quando se reflete sobre o ensino norteado pela diversidade cultural, com os diferentes grupos sentindo-se contemplados, evita-se, por exemplo, o desconforto cultural das populações quilombolas no processo da escolaridade monocultural, que não percebe suas expressões religiosas, musical, culinária e referentes à oralidade. O etnoletramento possibilita a articulação de muitas práticas pedagógicas, permitindo um questionamento: como a emergência do etnoletramento se dá nas escolas de educação básica no Brasil?

No modelo de ensino tradicional, que tem sido questionado, o professor é cobrado por suas práticas em sala de aula, considerando que este é apenas mediador do conhecimento, não permitindo ao aluno a escolha das ferramentas que lhe são mais adequadas, indicando os caminhos a serem percorridos no propósito de atingir os objetivos do processo de ensino e aprendizagem (Freire 1996). Considerar as metodologias que sugerem o etnoletramento indica um comportamento mais amplo na escolaridade, onde os atores têm maior troca de valores, na dinâmica da complementaridade, garantindo a alteridade na qual os grupos invisíveis são vistos no seu processamento cultural, tais como: fala, mitologia, música, dança e jogos, em processo lúdico, aproximando a africanidade, por exemplo, dos quilombolas, num processo horizontal com outros nomos eurocidentais da escola, que antes eram únicos e absolutos, caracterizados numa escola 
monocultural, da verticalidade da hegemonia imagética do euro-hetero-macho-autoritário (Prudente 2019d). Isto caracteriza um processo mais amplo e desejável das relações étnico-raciais no Ensino Básico.

Este artigo tem por objetivo trazer ferramentas que auxiliem o processo de articulação do etnoletramento em escolas de Educação Básica. Para tanto, traz seu aporte teórico ancorado principalmente na obra de Freire (1996), que é um dos precursores do letramento e de um possível etnoletramento, como formas de libertação do ser humano, bem como se vê em pesquisas atuais, a exemplo da dissertação de Trevisan (2019), que aponta diferentes caminhos às práticas de letramento.

Outra possibilidade aqui apontada é a dimensão pedagógica do Cinema Negro, que traz em seu repertório as pesquisas de Prudente (2018, 2019c), como a articulação de uma imagem de afirmação positiva acerca da população negra, como elemento de estímulo para um possível letramento nas relações étnico-raciais.

Neste artigo, propõe-se a provocação de um diálogo entre novas emergências pedagógicas, a saber o etnoletramento e a dimensão pedagógica do Cinema Negro, como elementos de plenitude do ser humano, nas suas relações étnico-raciais nos espaços educacionais, pensando em que medida estas possibilidades concorrem para a contemplação dos traços culturais ibero-ásio-afroameríndio como maioria minorizada, a exemplo dos grupos quilombolas, que são vítimas da invisibilidade dada pela euro-heteronormatividade, que caracteriza a escola monocultural.

\section{A DIMENSÃO PEDAGÓGICA DO CINEMA NEGRO EM CONTEXTOS EDUCACIONAIS DO ETNOLETRAMENTO}

Embora a origem bantu de quilombo seja refúgio beligerante (Munanga 1996), no Brasil contemporâneo, quilombo é uma ressignificação que implica um lugar onde se reúnem pessoas de relações de existência comum e que se identificam por traços semelhantes, eleitos como fator de identidade e, sobretudo, razão de autopreservação, na perspectiva de afirmação humana (Castilho 2011).

A dimensão pedagógica do Cinema Negro, neste artigo, traz à tona a reflexão acerca da inquietude humana em relação às formas de representação da realidade em diferentes espaços e contextos. Em um imaginário social, há ênfases para estas representatividades alternativas, em detrimento do comportamento escolar normativo convencional, que se vê geralmente no cotidiano. Essa revolução simbólica é vista como subversão da ordem e como uma tentativa de instituir outras formas de produção de conhecimento (Prudente \& Silva 2019c). 
Como parte de uma revolução tecnológica, o cinema traz mudanças de paradigmas ao lidar com a informação em sua essência, em uma perspectiva de evolução constante dos movimentos (Deleuze 1985). Nesse sentido, a arte cinematográfica apresenta diferentes dimensões epistemológicas e permite, na temporalidade, relações atemporais, como tem sido demandada, por exemplo, no processo religioso, possibilitando a populações ribeirinhas e, notadamente, quilombolas a comunicação com as suas ancestralidades, cultivando sua força vital pelo resgate de identidade sob uma perspectiva ontológica, na qual se humanizam em relação paradigmática com ancestrais como Orixás, Iaras, Xangôs, entre outros. Isso pode ser visto, por exemplo, no filme "Quilombo" (1984), de Cacá Diegues, cujo personagem Zumbi reoxigena a sua força na comunicação com o imaginário da personagem Acotirene. Como em outros grupos, as relações comunais nos quilombos se dimensionavam, sobretudo, por um processo lúdico de circularidades rituais, nas quais a música e a dança ocupavam elemento substancial que mostrava testemunho de amizade no processo de confraternização ritual, como uma doação dadivosa (Mauss 2003).

Vale ressaltar que o cinema enquanto produtor de sentidos epistemológicos revolucionários (Deleuze 2009) reafirma a compreensão da imagem-movimento, que se vincula também à realidade em questão. Diferentes percepções desse movimento epistemológico do Cinema Negro levam à reflexão de seu papel enquanto agente de interação entre as representações reais e imaginárias. Isso ocorre em uma fusão simbólica, que ajuda a constituir uma dimensão pedagógica para essa forma de expressão, na medida em que os filmes que tratam a africanidade no âmbito do quilombismo, lembrando Abdias do Nascimento (1980), permitem o resgate da identidade cultural do educando quilombola na dinâmica da dimensão pedagógica do Cinema Negro, no qual o quilombola ensina a sociedade sobre como ele é e como deve ser tratado, caracterizando aí o seu lugar de fala, que passa pelo etnoletramento, como Paulo Betti e Clóvis Bueno, que buscaram mostrar a visão de mundo quilombola no filme "Cafundó" (2005).

Esse movimento relacionado às epistemologias da dimensão pedagógica do Cinema Negro pode ser a mola propulsora de transformações nas práticas educacionais capaz de ampliar o questionamento da dominação efetivada pela euro-heteronormatividade. Relacionando desta maneira as dimensões do cinema à possível mudança de paradigmas, que são fundamentais ao etnoletramento na educação das relações étnico-raciais dos quilombolas, termo de origem banto, é oportuno mostrar sua influência na língua portuguesa, que é fundamental no processo de escolaridade (Prudente \& Gilioli 2013:87-88): 
A influência dos idiomas bantos, notadamente o quimbundo, o umbundo e o quicongo, foi decisiva para a configuração da língua portuguesa no Brasil, cuja forma é consideravelmente mais parecida com a dos países africanos - não por acaso - do que com o português de Portugal. E, entre os idiomas africanos que formaram a língua portuguesa no Brasil, os de origem bantu foram os predominantes.

A dimensão abordada nesse contexto refere-se à possibilidade de se materializar com o cinema a ontologia das relações entre os sujeitos, em um processo de transformação mútua entre eles e o mundo. Essa característica assume uma perspectiva pedagógica, a partir do momento que passa a ter um caráter de construção de novos conhecimentos. A dimensão pedagógica do Cinema Negro traz novas possibilidades de superação dos estigmas raciais e sociais, por meio de outras visões do negro e do quilombola, na condição de maioria minorizada, enquanto expressão miscigênica do ibero-ásio-afro-ameríndio (Prudente, 2019d), tão logo eles iniciem um processo de afirmação da imagem que querem ter para si, contrariando a visão eurocêntrica da imagem do euro-heteromacho-autoritário, determinada pela euroheteronormatividade (Prudente 2019d).

As abordagens de uma dimensão pedagógica do Cinema Negro são apontadas por Prudente (2018), na tentativa de expandir a importância da expressão subjetiva da imagem do negro na sociedade contemporânea, por meio da arte na era tecnológica em que se encontra a humanidade, passando de um tempo pautado na máquina para outro baseado na informação, cuja representação tem mais peso (Prudente 2018).

Neste contexto, denota-se que as pessoas estão muito preocupadas em apresentar uma imagem melhor de si mesmas. Este comportamento indica o deslocamento do capitalismo de produção para o capitalismo de sedução (Lipovetsky \& Serroy 2015), na medida em que, na era tecnológica da informação, as relações abstratas da representação se tornaram mais importantes do que as relações concretas do fato (Prudente \& Silva 2019). Com isso, o sujeito passa a poder ter uma imagem que ele próprio constrói de si, destacando-lhe, obviamente, os fatores positivos associados.

O Cinema Negro tem origem no Cinema Novo, de Glauber Rocha. A emergente categoria em questão tem sido utilizada como forma de oportunizar visibilidade, contribuindo com o resgate da ontologia do negro nas realizações cinematográficas (Prudente 1995). Nesse movimento, destacam-se ações de uso afirmativo da imagem do afrodescendente e também como meio de reparação do processo de perdas historicamente dadas aos povos de culturas estranhas aos nomos eurocaucasianos, como se observa na tentativa de fragmentação dos traços epistêmicos da 
ibericidade, da asiaticidade, da africanidade e da amerindidade (Prudente 2019c).

O Cinema Negro consiste numa renovação conceitual para expressar a diferença do posicionamento sociocultural dos afrodescendentes. Essa nova perspectiva cinematográfica tem procurado elaborar uma imagem afirmativa do negro e da sua cultura (Prudente 2008). Nesse sentido, é relevante buscar-se a apropriação do conceito de Cinema Negro e sua dimensão pedagógica, para contribuir com as práticas de etnoletramento em espaços escolares.

O Cinema Negro (Prudente 2008) pode apresentar dois vetores. O primeiro, liderado por Jeferson $\mathrm{De}^{1}$, denominado de Dogma Feijoada (Rodrigues 1988), o qual se caracterizou como um movimento de diretores negros de São Paulo. Esse vetor, que tem suas origens no final da década de 1990, preconizava a necessidade de ressignificação das imagens e representações sobre o negro no cinema brasileiro.

A partir do lançamento do manifesto "Dogma Feijoada", em 2000, escrito pelo cineasta Jeferson De, inspirado no cineasta Ari Cândido, o movimento buscou realizar filmes centrados na temática racial, contribuindo para um conceito de Cinema Negro brasileiro, que passou a influenciar a realização contemporânea de cineastas autodeclarados afrobrasileiros. As produções cinematográficas dessa corrente têm como especificidade a participação única e exclusiva de negros (Rodrigues 1988). É um cinema que só admite a participação do negro no seu processo de criação e de produção.

O outro vetor é representado pela Mostra Internacional do Cinema $\mathrm{Negro}^{2}$, cujo curador é o cineasta Celso Prudente. O Cinema Negro é a filmografia buscando a imagem de afirmação positiva das minorias como um todo. A décima quinta edição anual deste movimento foi realizada em parceria com o Serviço Social do Comércio (SESC) do estado de São Paulo, e aconteceu na sua unidade de Vila Mariana, de 6 a 11 de agosto de 2019. Segundo o diretor do SESC-São Paulo, Danilo Santos de Miranda, “a Mostra Internacional do Cinema Negro busca, no estímulo à produção, difusão e reflexão, integrar seus agentes e demais públicos interessados às questões prementes nesse campo há mais de uma década" (Miranda 2019:4).

Esses dois movimentos do Cinema Negro são precursores de um processo de tentativa de

1 Jeferson De é um cineasta brasileiro afrodescendente, nascido em Taubaté, interior de São Paulo. Estudou cinema na Universidade de São Paulo (USP), onde foi bolsista da Fundação de Amparo à Pesquisa do Estado de São Paulo (FAPESP), com a pesquisa "Diretores cinematográficos negros". Em 2000, publicou o manifesto "Dogma Feijoada".

2 A Mostra Internacional de Cinema Negro é um evento que exibe a produção cultural negra e contribui para que fique cristalina a sua participação no desenvolvimento cultural, econômico e social do Brasil, ressaltando também que o negro é ator social participante desse processo, e não apenas mero expectador. 
mudanças dos paradigmas até então difundidos pelos meios audiovisuais brasileiros. A Mostra Internacional do Cinema Negro e o "Dogma Feijoada" possibilitam uma nova apreciação estética da cultura africana, por meio de filmes temáticos. Embora existam diferenças ideológicas nas raízes das duas tendências do Cinema Negro, é importante dizer que ambas se preocupam em dar ao negro sua posição de destaque, que fora ultrajada durante grande parte do processo histórico do país.

As realizações desta vertente de cinema propõem a saída do negro do lugar de simples elemento de figuração, tornando-o protagonista dos filmes e, consequentemente, da vida. É um processo que visa levar à possível construção de uma imagem de positividade sociocultural da população negra, na dinâmica da sua especificidade, como no caso dos quilombolas, levando para as telas uma imagem de afirmação positiva da africanidade (Prudente 2019a), ou seja, tem a preocupação de transmitir as qualidades do negro, que outros tentaram historicamente negar. Neste processo de reconstrução a partir de uma imagem positiva é que se delineia a liberdade nas representações cinematográficas.

É um importante movimento para romper estigmas, criando oportunidades para as populações negras. Trata-se de uma dinâmica para desconstruir a produção eurocêntrica, que se deu no intuito de concorrer para furtar das populações negras seus direitos de cidadania, aviltando sua representação de positividade (Prudente 2019a, 2019b).

A dimensão pedagógica do Cinema Negro (Prudente 2019b), com realizações étnicocinematográficas, extrapola a filmografia que tentava fixar o negro em papéis de escravidão, por meio da empregada doméstica, da faxineira e dos bandidos. Tais figuras queriam alicerçar um imaginário social pejorativo sobre o negro, reforçando uma dominação eugênica, configurada também na dominação de gênero, que ocorreu da Chanchada à Pornochanchada, na medida em que a imagem da mulher ficou limitada na configuração de objeto sexual, ainda como reflexo da violência sofrida do senhor de engenho (Senna apud Carvalho \& Domingues 2017). Essa situação deu-se concomitante à aparição da genialidade de alguns artistas negros, notadamente o fenomenal Grande Otelo, considerado o melhor ator latino-americano em todas as linguagens da dramaturgia por Orson Wells (Senna apud Carvalho \& Domingues 2017). Com o advento do Cinema Negro, projeta-se a possibilidade de uma representação artística que servirá de aporte à visibilidade das qualidades urbanas e rurais do negro, na condição de depositário de traços telúricos da africanidade, como é o caso dos quilombolas, que combinam 
o trabalho na terra aos valores ressignificados da cosmovisão africana primogênita. Os holofotes são postos nos elementos da cultura africana (Prudente 2019b), que é estranha aos nomos da cultura eurocolonial, precisando ser vista e reconhecida pela sociedade e na escola, impregnada da monoculturalidade.

Nota-se, na indústria cinematográfica brasileira, a invisibilidade do negro, sobretudo absoluta ausência em personagens protagonistas. A sociedade nega a participação do negro como elemento primordial na construção do país, tentando impor os estereótipos de subalternidade. Há muito é questionado o fato de um país como o Brasil ter a sua maioria, o afrodescendente, sem representatividade nas produções cinematográficas, concorrendo para sua exclusão em outros setores da sociedade.

O campo do Cinema Negro e a sua dimensão pedagógica (Périgo 2018) ampliam as possibilidades de discussão das relações étnico-raciais. É por meio da arte cinematográfica que se traz para a sociedade a discussão da não conformidade do negro em ser "coisificado" na sua atuação social, razão pela qual é estruturante no conceito da dimensão pedagógica do Cinema Negro uma filmografia comprometida com o oprimido, na luta ontológica da horizontalidade da imagem do ibero-ásio-afro-ameríndio, contra a verticalidade da hegemonia imagética euro-hetero-machoautoritário (Prudente 2019d).

Com a dimensão pedagógica do Cinema Negro, o afrodescendente no cinema verbaliza suas qualidades enquanto ser humano, superando o processo unidimensional de uma sociedade que é dada por um modelo euro-hetero-machoautoritário $^{3}$, que se estabelece em um axioma único meramente pelo fato de ser branco (Sartre 1960). Esta relação étnico-cinematográfica da africanidade traz o negro em primeiro plano, desarticulando o processo eurocêntrico de massificação, descolonizando hábitos e conceitos, como aconteceu no filme "Alma no Olho" (1973), do cineasta negro Zózimo Bulbul (Carvalho 2013), trocando o terno pelo seu corpo nu, que só ocorreria em um lugar de autonomia, como no quilombo. O filme "Alma no Olho" aborda um negro que está em um desterro psicológico, na medida em que está com a roupa do opressor, o terno, no qual se sente preso (Prudente 2019a). A partir do momento que vai se despindo dessa roupa, em favor do seu corpo africano, ele vai se libertando de uma opressão, buscando uma volta

3 O euro-hetero-macho-autoritário - silogismo de Celso Prudente - tem como objetivo demonstrar a verticalidade nefasta peculiar do poder que a expressão europeia, branco-ocidental exerce sobre as minorias, tornando-as, ainda, caracterizadas na condição subalterna, diante do mito da superioridade racial do homem (hetero/macho) caucasiano. Trata-se do sentido europeu do poder masculino, do macho que se estabelece como uma força impositiva para manifestações que lhes são diferentes (o negro, o homossexual, a mulher...) (Prudente 2019d). 
à natureza quilombola, que se dá na condição do seu corpo nu (Prudente 2019a).

Nesse contexto, percebe-se a arte cinematográfica como uma questão política de afirmação e contestação, ou seja, uma produção de sentidos e significados para a construção de uma estética emergente, que é uma nova realidade e, por conseguinte, uma nova epistemologia. $\mathrm{O}$ Cinema Negro espelha a autêntica diversidade brasileira (Prudente 2019a). Embora isso seja muito positivo, não se pode esquecer que o cinema tem o real valor da mensagem transmitida, pois as palavras e ideias promoverão atos posteriores. Esse movimento de transmissão de valores, de uma nova forma de se referir a um grupo populacional, que é baseada em suas próprias indicações, é que constitui esta dimensão pedagógica do Cinema Negro, a qual pode ser apresentada como um eixo norteador na discussão das relações étnico-raciais no contexto educacional, em favor do respeito à diversidade, buscando dar voz às culturas negra e quilombola. Pode-se, com o cinema, orientar o educando na perspectiva de identificação de discurso e ideologia, na relação emocional do espectador com a criação do diretor em relação a determinado espaço e momento (R. Almeida 2017). A amplitude comunicativa do cinema se dá no processo de resgate da dignidade e da cidadania, enquanto contemporaneidade inclusiva estrutural à dimensão pedagógica do Cinema Negro, na luta ontológica contra o anacronismo excludente da verticalidade da hegemonia imagética do eurohetero-macho-autoritário (Prudente 2019d).

O cinema é visto como instrumento de superação do eurocentrismo, para além da tentativa de coisificação, imposta pela euroheteronormatividade (Prudente 2019d). Esta arte cinematográfica contribui, portanto, para uma transposição que vai além dos ideais eurocêntricos, que tentam impor, em primeiro plano, a formação de uma cultura hegemônica branca (Rodas \& Prudente 2009). A dimensão pedagógica do Cinema Negro é um elemento libertador, que busca a visibilidade do negro e do quilombola na dinâmica da africanidade, concorrendo para a construção de uma imagem de afirmação positiva.

Procurando compreender este assunto, baseando-se em uma perspectiva de etnoletramento, é possível identificar as possibilidades de luta e resistência a modelos eurocêntricos, que tentam inferiorizar a participação da imagem de horizontalidade do ibero-ásio-afro-ameríndio ${ }^{4}$, em uma sociedade construída a partir de um único modelo cultural, o monoculturalismo autoritário

4 Trata-se de uma categoria autoral que compreende a unidade de todos os povos de culturas ibéricas, asiáticas, africanas e ameríndias, na medida em que o ponto identitário é a língua portuguesa, que se faz na condição de povos que foram vítimas da colonização euro-ocidental (Prudente 2019d). 
da história única (Adichie 2019).

Este conceito emergencial do Cinema do Negro oferece outra forma de compreensão do afrodescendente, a partir de uma explicação subjetiva e de teluricidade axiológica do negro no imaginário do quilombismo. Ele se posiciona dizendo ao estabelecido como ele é, não como o estabelecido o vê, mas como ele se define enquanto negro e como anseia ser visto. Trata-se de uma explicação pessoal de subjetividade própria, na qual o negro se retrata enquanto protagonista do processo histórico. Essa possibilidade de representação a partir do próprio negro é que se articula ao emergente conceito de dimensão pedagógica do Cinema Negro.

Esta categoria conceitual apresenta uma reflexão e aponta também à autonomia de outros fatores, como religiosidade, musicalidade e "quilombidade", onde expressa uma ontologia que concorre nos filmes à construção da imagem de afirmação positiva. Contribui para a desarticulação da imagética de submissão perante um mundo que foi construído em padrões da brancura (Sartre 1960), como se vê no já mencionado filme “Quilombo", de Cacá Diegues, uma organização na axiologia africana, em que a religião, a música e a dança passam por um processo de "orixalidade", denotando a autonomia da cultura quilombola. Nesta linha de compreensão, Prudente (2002:39) mostra a africanidade religiosa como elemento

fundamental do universo negro:

A base branca de orixalidade que revela
o mistério da força do Orum, na qual
Olodumaré se configura como alicerce
invisível no panteão da mitologia
iorubá e se apresenta para os devotos
nos momentos sagrados das danças,
que interpretam a sinfonia negra dos
tambores mágicos.

Essas percepções podem ser exemplificadas quando um adolescente afrodescendente, de natureza quilombola, consegue se perceber identificado com o herói nas realizações do Cinema Negro, desenvolvendo uma imagem positiva de si mesmo em relação à sociedade, identificando-se com o personagem Zumbi (Pompeu), no filme "Quilombo". Essa criança poderá se visualizar nessa sociedade, identificando-se com os modelos discutidos que representam sua concepção racial, aproximando-se da realidade cidadã, concorrendo contra as assimetrias sociorraciais.

Outro aspecto nessa discussão é como o etnoletramento alinha-se com a possibilidade da compreensão do afrodescendente na dinâmica quilombola, como imagem de horizontalidade do ibero-ásio-afro-ameríndio enquanto maioria minorizada, compreendendo-se no discurso social em que está inserido como sujeito. Isto na medida em que o quilombola/negro/afrodescendente/ miscigênico/ibero-ásio-afro-amerindío, que é 
minoria diante da euro-heteronormatividade, aprende ensinando como o mesmo quer ser visto pela sociedade. A categoria conceitual da dimensão pedagógica do Cinema Negro, junto com o etnoletramento, seria a possibilidade de construir uma leitura crítica da realidade, influenciando positivamente em como o negro se posiciona diante do processo social (Prudente 2019e).

\section{0 ETNOLETRAMENTO}

A busca pelo entendimento do etnoletramento precisa ser delineada, demonstrando os letramentos que são pertinentes às práticas pedagógicas, na perspectiva das relações étnico-raciais. Apresentase, portanto, uma breve abordagem histórica dos letramentos, observando-se como estes debates influenciaram o processo da discussão do letramento no Brasil. As discussões, a partir de uma perspectiva pedagógica, implicada em nova prática epistemológica, demonstram os conceitos de práticas e eventos de letramentos (Trevisan 2019).

Leciona Picolli (2010) que a discussão sobre letramentos tem início na segunda metade dos anos 1980. Isso se deu com as ciências linguísticas e a educação se tornando precursoras que influenciaram o tema nos espaços brasileiros. Ao contrário dessa afirmação, os pesquisadores Lankshear \& Knobel (2006) consideram que as discussões sobre letramento remontam à década de 70, nos EUA, no processo da reforma curricular norte-americana, impactada pela pedagogia freireana, juntamente com estudos socioculturais da década em questão.

\begin{abstract}
A educação literária freireana era, então, uma integral componente de uma pedagogia radical e politizada projetada propositadamente para estimular ação para mudança. $\mathrm{Na}$ verdade, capturou a imaginação, respeito e apoio de muitos acadêmicos e ativistas políticos em Primeiros Países - particularmente, na América do Norte -, além de serem adotadas como base filosófica para programas nacionais e regionais de alfabetização de adultos em vários países do Terceiro Mundo (Lankshear \& Knobel 2006:10).
\end{abstract}

Estes dois vetores das discussões apresentam resultados comuns no contexto histórico do período mencionado, de modo que as práticas de letramento estão voltadas para a formação de uma mão de obra com foco no mundo do trabalho, desconsiderando a educação como emancipação social. Sendo assim, a pedagogia de Paulo Freire torna-se um dos motivos que propulsionam as discussões sobre o letramento, pois sua contribuição, que é muito importante para a educação, desenvolve uma consciência crítica sobre o cotidiano.

Estes estudos promoveram um crescimento significativo na perspectiva sociocultural (Gee 1996 apud Lankshear \& Knobel 2006). Acredita-se 
que, com isso, foi-se aprimorando a influência de estudos acerca da linguagem e das ciências sociais, em uma dimensão conceitual e teórica das práticas de letramento, conforme se observa em Gee (1996 apud Lankshear \& Knobel 2006:16):

\begin{abstract}
Do ponto de vista sociocultural, o letramento é uma questão de práticas sociais. Os letramentos estão ligados a instituições sociais, instituições e relacionamentos culturais, e só podem ser entendidos quando estão situados dentro de seus contextos sociais, culturais e históricos.
\end{abstract}

Para se pensar em etnoletramento, devemos dimensionar a prática pedagógica para além da sala de aula, rompendo as barreiras de uma monocultura escolar, ou seja, o professor deve sair de um universo binário de educador/lecionador para uma percepção enquanto intermediador/ interventor na diversidade, considerando, assim, o aluno como possível protagonista, e não apenas como ouvinte, além de compreender como esse processo social influencia suas relações étnicoraciais com negros, quilombolas, ribeirinhos, etc., como minorias miscigênicas.

Esta prática pedagógica está voltada para além do ato de alfabetizar, assim como para além do ato de lecionar (Soares 2004). Sendo o etnoletramento "uma consciência fonológica e fonêmica, identificação das relações fonemagrafema, habilidades de codificação e decodificação da língua escrita” (Soares 2004:15), essas complementaridades concorrem para consolidar as demandas de "práticas sociais de leitura e de escrita mais avançadas e complexas que as práticas do ler e do escrever resultantes da aprendizagem apenas do sistema de escrita" (Soares 2004:15).

Proporcionadas pelo etnoletramento, as práticas pedagógicas devem permear a imersão das crianças na cultura escrita, bem como sua participação em experiências variadas com a leitura e a escrita, promovendo, deste modo, o conhecimento e a interação com diferentes tipos e gêneros de material escrito, considerando-se que o seu aprendizado vai além do simples ato de alfabetizar. Assim, busca-se sair da individualidade e priorizar o conhecimento de habilidades básicas e a aprendizagem de transcrição da fala para o sistema de código escrito, como atividades interacionistas, em uma possível amplitude das relações étnico-raciais do negro/quilombola enquanto maioria minorizada, enquanto iberoásio-afro-ameríndio (Prudente 2019d).

Assim, tudo está atrelado ao modo como se concebe a alfabetização no processo discursivo. Considera-se, nesta perspectiva, o dimensionamento das relações de gêneses do aditamento humano, ou seja, a sociogênese, implicando dimensões tais como a pronúncia/falar, o entendimento/pensar e o sentimento/sentir da criança, sendo estas medidas 
que ganham sentido no processo das relações (Smolka 2014). O processamento das relações sociais deve considerar, com efeito, o fundante crédito de mediação e de participação, desvelando o outro/ diferente na construção cognitiva da criança, tal qual a ideia de Smolka (2014), em que a expressão/ linguagem funciona enquanto produtora de consagração da história e da cultura na constituição dos sujeitos, como demanda da subjetividade e do saber, sendo isso produção e produto humano, afetando, constituindo e transformando o desenvolvimento e o funcionamento intelectivo do sujeito. Segundo Smolka (2014:1):

\begin{abstract}
Um argumento central nessa perspectiva é o da natureza social, ou da sociogênese do desenvolvimento humano. Isto significa que os modos de agir, pensar, falar, sentir das crianças vão se constituindo e adquirindo sentido nas relações sociais. Destacase, assim, a fundamental importância da mediação e da participação de outros na construção do conhecimento pela criança, bem como a concepção de linguagem como produção histórica e cultural, constitutiva dos sujeitos, da subjetividade e do conhecimento. Ou seja, a forma verbal de linguagem como modo de interação - como produção e produto humanos - afeta, constitui e transforma o desenvolvimento e o funcionamento mental dos sujeitos.
\end{abstract}

Ao se considerar as práticas de escritas que foram construídas ao longo do processo de formação da sociedade, sua transformação é nítida, as quais devem ser voltadas para bases conceituais da aquisição de leitura e escrita associadas a uma perspectiva sociocultural do ensino e da aprendizagem do indivíduo. Isso deve vir respaldado em um conjunto de normas e códigos atrelados à interação social, no contexto em que o sujeito está inserido, contribuindo, assim, para a construção das relações étnico-raciais (Prudente 2019c). A prática social convencional do letramento tem como finalidade atingir processos interpretativos do ator escolar individualmente e independente de possíveis fatores externos que possam interferir na prática de ensino. Dessa maneira, deixando à margem as culturalidades estranhas à euro-heteronormatividade (Prudente 2019d), percebendo-se as desarticulações das relações étnico-raciais do afrodescendente conjugadas à escolaridade, é que se reestabelece a emergência do etnoletramento, permitindo também a dinamização cultural do quilombismo (Nascimento 1980), em oposição ao modelo que apenas mostra o quilombola como minoria, enquanto imagem da horizontalidade do iberoásio-afro-ameríndio (Prudente 2019d).

O etnoletramento sugere a escola com mais espaços de convívio amplo, concebendo outras realidades, compartilhando locais, objetos e pessoas. Assim, ele processa a ressignificação, moldando sentido e significado, desarticulando a monocultura de ensino único e universal, 
adentrando nos diversos aspectos que são moldados na dinâmica da realidade dos seus sujeitos. A ressignificação abordada sobre o letramento traz reflexões a respeito das práticas socioculturais, históricas e sociais como variáveis do cotidiano escolar. Desse modo, é proposto que as práticas são:

Modos de estar no mundo, de compreender a realidade e de estabelecer sentido, partilhados social e historicamente. Isso implica dizer que elas não são jamais individuais, a despeito de serem atividades realizadas individualmente pelos sujeitos. Mas também significa dizer que exercitam em culturas específicas, o que nos faz interrogar não apenas acerca das relações históricas nas quais se produzem, mas das circunstâncias escolares e educacionais em que foram geradas (Vidal \& Biccas 2008 apud Bunzen 2010:103).

As discussões em questão apresentam uma necessidade de reflexão sobre o etnoletramento nos contextos de práticas pedagógicas, somado com uma visão contemporânea, promovida pela apropriação de mídias digitais que envolvam a concepção negra quilombola no espaço cinematográfico. Isso extrapola as analogias propostas e amarradas no letramento tradicional. Diante dessa interposição, apresentamos a discussão sobre o etnoletramento e a dimensão pedagógica do Cinema Negro, considerando as epistemologias emergentes (Prudente 2019a, 2019b, 2019c, 2019e).

\section{O ETNOLETRAMENTO E A DIMENSÃO PEDAGÓGICA DO CINEMA NEGRO COMO EPISTEMOLOGIAS EMERGENCIAIS}

As dimensões previamente abordadas acerca do etnoletramento indicam uma visão de fronteira. Esta visão é distribuída em diversas funções, inclusive no que tange às limitações, às superações e aos respaldos que podem ser atribuídos a estas novas possibilidades de leitura e compreensão social (Prudente 2019c).

Para se entender a temática do letramento como propriedade da língua escrita na dinâmica da cidadania e da legitimidade cultural, considerase o aprendizado como elemento vinculado ao signo verbal escrito. As contribuições sugerem que a modalidade da língua, em seus processos naturais e de ensino, seja vista como um processo cultural, como parte integrante do cotidiano da convivência humana, embasada em um aprendizado formal dos conhecimentos ensinados. Nesse caso, são de suma importância os conceitos sobre etnografia, sociolinguística, letramento, currículo e interculturalidade, para que a abrangência da pesquisa e a temática se portem diante dessas diferentes categorias de análise e múltiplas frentes teóricas.

Para a compreensão desses estudos, precisamos apreender o significado do radical "etno", que, adicionado a algumas palavras do nosso verbete 
português, traz um sentido literal da palavra escrita, por exemplo etnoletramento, atribuído ao ao ensino da escrita associada a um determinado grupo social que compartilha culturas, origens e histórias (S. Almeida 2015).

Afirma-se que, ao entrar em campo, o pesquisador deve ter em mente algumas questões, como: “[...] o que pesquisar? Qual o objeto de estudo? O que focalizar? O que observar?, pois a partir daí é possível elaborar e elencar as perguntas norteadoras da pesquisa, ou seja, nenhuma pesquisa deve partir do nada, pois levará a lugar nenhum" (Sousa 2006:10-11). Todo trabalho deve ser elaborado minuciosamente refletindo sobre os mínimos detalhes da pesquisa. Ao elencar perguntas orientadoras, Erickson (1986:119161) argumenta que o pesquisador minimizará o caminho a ser percorrido levando em consideração as contrapartidas que poderão interferir no bom andamento da investigação.

É nesta linha de abordagem que se insere o etnoletramento como uma possibilidade de uma escolaridade mais ampla, baseada na construção contínua do conhecimento por meio da pesquisa, rompendo com o ensino monocultural, tratando o conjunto da materialidade e imaterialidade do cotidiano escolar, mas atento à especificidade dos atores. É neste contexto que se observa a inclusão do afrodescendente/ negro/quilombola, do amerindiodescendente/ indígena, do ibericodescendente/português/espanhol, na dinâmica miscigênica do ibero-ásio-afro-ameríndio, como se vê também na cultura cuiabana, de natureza amazônica (Prudente \& Silva 2019). Esta é a razão pela qual devemos caracterizar as especificidades, respeitando, assim, esses limites e as suas fronteiras, compreendidos como um todo, considerando a interação cultural. Dessa maneira, o etnoletramento tem mais possibilidade de eficácia na aplicabilidade escolar. Esta nossa preocupação encontra ancoragem no diálogo com Erickson (1988), quando aborda a questão da especificidade na etnografia:

[...] Etnografia significa literalmente
escrever sobre os outros. O termo
deriva do verbo grego para escrita
e do substantivo grego (ethnos) que
se refere a grupos de pessoas que
não foram gregos; por exemplo:
társios, persas e egípcios. A palavra
foi inventada no fim do século XIX
para caracterizar cientificamente os
relatos de narrativa sobre os modos
de vida dos povos não ocidentais.
Monografias etnográficas diferiam
das descrições em livros que foram
escritos por viajantes e que se
tornaram populares entre os europeus
ocidentais educados com um interesse
no exótico. Relatos de viajantes
foram vistos por antropólogos
como incompletos e superficiais.
A etnografia foi considerada como
mais completa e cientificamente
substantiva (Erickson 1988:1083).

No estudo dos outros, não ocidentais, geralmente se desconsidera o sentido da sua cultura no âmbito do conhecimento que pressupõe as relações de aprendizagem (Erickson 1988). Talvez essa perspectiva, do "outro", 
impregnou as ciências sociais, dificultando a multiculturalidade na escolaridade, em razão do seu caráter monocultural, de tal sorte que urge a necessidade do etnoletramento como possibilidade de ampliação dos valores culturais no ensino, garantindo respeito à diversidade, onde se localiza a emergência do quilombismo (Nascimento 1980) na escola que tradicionalmente desconsidera o outro como axiologia estranha ao valor euro-ocidental (Prudente \& Silva 2019).

\section{A PRÁTICA PEDAGÓGICA COMO ALIADA NO PROCESSO DE ETNOLETRAMENTO}

Nesse momento, devem ser discutidas todas as ferramentas que possam atingir os objetivos propostos à educação. No que tange ao etnoletramento, na perspectiva da prática pedagógica, com uma visão consciente e participativa sobre o seu uso na melhoria da qualidade do ensino, foi discutido a multidimensionalidade do ato educativo. Considera-se que a prática educativa está vinculada a traços culturais que podem ser compartilhados de forma subjetiva e, portanto, esta prática pedagógica varia de acordo com a compreensão em questão (Gimeno Sacristán 1999).

Nesta dinâmica, nota-se que, no Brasil, desde o período da colonização, no século XVI, a partir da chegada dos portugueses, já se estabeleceu uma cultura linguística de bilinguismo, que se mostra ainda frágil, na medida em que se tratava de um lugar poliétnico, onde o multilinguismo era inequívoco, como se vê nas centenas de línguas dos povos ameríndios originários. A língua lusa, ibérica, dos portugueses, somada às línguas africanas, algumas preservadas pelos escravizados e quilombolas, e termos ameríndios formaram uma dinâmica linguística singular, adotada como uma única língua oficial. Nota-se a fusão de línguas, que se caracteriza, aqui, na expressão ibero-ásio-afro-ameríndio (Prudente 2019d), formando uma língua lusitana de inequívoca especificidade, tornando-a fala singular na dinâmica lusofônica, feita a partir de um processo original de multilinguismo, cujo reconhecimento mostra fragilidade factual, na medida em que ainda é reducionista, tornando os vetores não ocidentais, como o africano e o ameríndio, um só elemento, no qual é apontada a bilingualidade tentando reduzir o multilinguismo, como negação ao multiculturalismo, apresentado equivocadamente no Brasil como se fosse único. Como se vê, as relações de multilinguismo apresentam processamento sociocultural e quando muito são observadas ainda como bilingualidade, como foi discutido por Salgado \& Dias (2010:148):

[...] quando o bilinguismo entra na atividade humana, os problemas não são somente linguísticos (ou sociais, ou psicológicos); eles podem interessar a muitos campos 
de conhecimento humano. Quando o bilinguismo "entra nas atividades do homem" estamos falando de bilingualidade.

A proposta de etnoletramento nas escolas de educação básica tende a promover uma metodologia que atenda não somente à necessidade da linguística, mas da caracterização e execução do contexto cultural em suas múltiplas línguas e complexidades. Estas são características fundamentais para as minorias étnico-raciais, que muito contribuíram para a formação cultural do país, hoje considerado um dos mais miscigenados do mundo, a exemplo da composição miscigênica que denominamos ibero-ásio-afro-ameríndio, que, embora negada, é detentora de diversos traços de formação dentro do plexo de abrangência da complementaridade (Merleau-Ponty 1994).

Em uma visão morfológica, etnossociolinguística e letramento são conceitos dissociados da palavra etnografia enquanto processo de conhecer. "Sócio" e "linguístico" apresentam uma teoria emergente, que vem a respaldar as orientações de cada uma dessas áreas de conhecimento (Erickson 1988), permitindo constituir, desta maneira, uma proposta de currículo para promover a elaboração de um planejamento voltado para suprir as necessidades de grupos étnicos, que estão na dinâmica de uma escola com determinadas características, como a escola quilombola, tendo em vista que a escolaridade tem sido estabelecida no autoritarismo do processo monocultural, em proveito do eurocentrismo, determinado pela euroheteronormatividade (Prudente 2019d).

No que tange à interculturalidade nas escolas, vale ressaltar que o domínio social é caracterizado por uma situação sociolinguística que apresenta uma estrutura fundamentada no "bilinguismo social e intercultural" (Maher 2007). Compreendese que as orientações sobre a sociolinguística devem formar um instrumento essencial nas práticas pedagógicas do professor (Maher 2007), contribuindo, assim, para um processo de ensinoaprendizagem voltado para a reflexão, em favor do respeito à diversidade, considerando, deste modo, a língua de diversos protagonistas dentro do contexto escolar.

Esses estilos comunicativos emergentes servem para demarcar fronteiras de identidade, de linguística e de princípios étnicos, os quais são elementos primordiais para os interlocutores do cotidiano escolar, dando ênfase ao processo de ensinoaprendizagem intercultural (S. Almeida 2015).

Assumindo um papel norteador de mediação de conhecimento, promoção de cultura e disseminação de variedades curriculares, a escola deve se manifestar por meio de diferentes letramentos, que se desdobram na interação entre as línguas faladas 
pelos alunos e pelos professores, ressaltando, ainda, critérios bilíngues com internalidade intercultural, seja ela branca ibérica, negra/preto africano ou vermelha ameríndia, considerando-se que, no caso específico do Brasil (Prudente 2018), o branco ibérico também é discriminado como o português burro e o espanhol nervoso, o amarelo asiático é negado como o japa "de pau pequeno", que "amarela na hora h", o vermelho ameríndio é vítima da depreciação como "perigo vermelho", incauto e indolente (Prudente 2018, 2019b). Essas discriminações se somam com o preto "africano, próprio para o trabalho pesado e lascivo".

Além da conscientização da escola, como parte fundamental no processo de ensino com uma perspectiva de respeito etnográfico, faz-se também necessário introduzir nas concepções pedagógicas do corpo docente a adoção dessa prática em seu currículo, pois se considera que o currículo por si só não é capaz de promover o etnoletramento, mas deve estar associado a práticas pedagógicas que colaborem significativamente para o processo de ensino-aprendizagem com concepções interculturais, sendo esta uma das possíveis conexões com a dimensão pedagógica do Cinema Negro.

Considera-se, nesta perspectiva, um currículo favorável às relações étnico-raciais do negro que, por sua natureza abrangente, comporta também as relações multilinguísticas, dadas pela dinâmica das culturas não ocidentais, observadas nos vetores africano e ameríndio que, reitero, quando vistos são tratados como vetor único. Portanto, as concepções que propõem estudos embasados na etnossociolinguística permitem a identificação de aspectos sociológicos, antropológicos, linguísticos e culturais que se afunilam nas práticas sociais das comunidades envolvidas no processo escolar (Prudente 2019e).

Considera-se, no Brasil, que somos culturalmente muito parecidos, com evidência, porém, para estudos na perspectiva de um povo que se destaca, enfatiza e valoriza sobretudo pelas lembranças monoculturais, em detrimento da amplitude dinâmica das relações étnico-raciais. Com base nisso, deveria se trazer para a prática pedagógica a interculturalidade, que promove o respeito à diversidade na demanda escolar (Gomes 2000), superando o anacronismo excludente (Prudente 2018), que enseja a escola monocultural.

É urgente a necessidade de conjugar a abrangência das relações étnico-raciais dos quilombolas, na qualidade de afrodescendente, como imagem de horizontalidade do ibero-ásioafro-ameríndio (Prudente 2019d), enquanto minoria no processo de escolaridade. Dessa forma, teremos uma aprendizagem poliétnica (Prudente \& Silva 2019), na qual o quilombola 
se torne sujeito, sendo ouvido no espaço escolar, onde costuma ser silenciado. Inferimos que, a partir de uma nova abordagem, a voz emergente da minoria, como os quilombolas, que antes era silenciada, pode se estabelecer agora como o decantado lugar de fala dos movimentos sociais, das minorias vulneráveis (Passos \& Prudente 2017), ganhando visibilidade, que lhe confere também a construção da imagem de afirmação positiva, dada pela contemporaneidade inclusiva substancial da dimensão pedagógica do Cinema Negro (Prudente \& Silva 2019), categoria emergente em que o afrodescendente/minoria ensina dialeticamente a sociedade com sintomas de democracia, como ela é e como deve ser tratada (Prudente 2019c).

\section{CONSIDERAÇÕES FINAIS}

O etnoletramento sugerido neste artigo levanta a possibilidade de realização de um letramento crítico e reflexivo (Soares 2004), que oportunize a compreensão do conjunto de todos os atores envolvidos na dinâmica sociocultural das relações de ensino formal, que têm sido silenciados pelo comportamento monocultural da escolaridade. O etnoletramento acomoda no seu seio a consideração das relações étnico-raciais dos quilombolas como afrodescendentes, na condição de minoria na horizontalidade da imagem do ibero-ásio-afro-ameríndio, que rompe com o autoritarismo da euroheteronormatividade (Prudente 2019d), que determina a imposição da verticalidade hegemônica imagética do euro-heteromacho-autoritário na escola (Prudente 2019e), sufocando as expressões materiais e imateriais do quilombismo (Nascimento 1980). As relações sociolinguísticas se estabelecem no letramento (Bunzen 2010), o qual não considera a perspectiva poliétnica (Prudente 2019e), razão pela qual este artigo se preocupa com o etnoletramento, na perspectiva de uma interação crítica (Freire 1996), comportando, assim, as relações multirraciais, que estabelecem a voz dos diferentes, caracterizados como culturas não euro-ocidentais, que encontram no etnoletramento a possibilidade de lugar de fala, superando o silêncio do subalterno (Spivak 2010) na dinâmica multicultural das relações étnico-raciais do ibero-ásio-afroameríndio (Prudente 2019d), em que se localiza o quilombola como sujeito na escolaridade.

A construção da categoria de dimensão pedagógica do Cinema Negro, que foi discernida por Celso Prudente, implica o discernimento do negro como autor/realizador cinematográfico, 
reconstituindo a sua própria história, tornando-se sujeito, superando o estereótipo de inferioridade e construindo sua imagem de afirmação positiva (Prudente 2019a). A intersecção dialética da dimensão pedagógica do Cinema Negro com o etnoletramento se dá na medida em que, na primeira, o quilombola, como sujeito, constrói a sua própria imagem, superando o estereótipo do anacronismo excludente dos meios de comunicação de massa (Prudente \& Silva 2019); na segunda, a dinâmica silenciada do quilombola na escolaridade ganha voz, quando o negado passa a ser também referência emergente no estudo que lhe era imposto, e que o desconhecia.

É evidente que o ensino atual vive uma realidade de mudanças, pois olhares estudiosos estão se voltando para a análise e a compreensão da cultura vinculada no conhecimento, embasadas em uma estrutura de etnoletramento (Soares 2004). Estes estudos trazem algumas caracterizações emergentes acerca das variações culturais que marcam certas comunidades, notadamente a quilombola, sendo apresentado também em um contexto histórico significativo, considerando-se as diversidades culturais.

Nesta abordagem, tornou-se importante destacar que as escolas e outras instituições de ensino devem dar ênfase nos aspectos sociolinguísticos e pluriétnicos, propiciando a riqueza da cultura local, em um plano de horizontalidade democrática, rompendo com o tradicionalismo dos grupos do poder estabelecido. Nesse sentido, a utilização da dimensão pedagógica do Cinema Negro como metodologia de integração da presença afro no contexto histórico, filosófico, sociológico e cultural da nossa sociedade pode ser relevante, pois leva em consideração a importância dos quilombolas como africanidade brasileira na formação das determinações pedagógicas do atual contexto educacional. Sua compreensão é imprescindível para o processo de formação de um aprendizado significativo e construtivo, caracterizando e enfatizando a vivência de cada seguimento cultural.

Este estudo tentou contribuir para a análise da dimensão pedagógica do Cinema Negro no contexto de etnoletramento, na dinâmica da Educação Básica, pensado sobre uma perspectiva quilombola. Porém, reconhecemos que, para melhor compreender esse processo, é necessária a contemplação de mais estudos sobre etnoletramento e sobre a própria aplicabilidade do Cinema Negro enquanto instrumento pedagógico, uma vez que suas referências ainda são escassas. 


\section{REFERÊNCIAS}

Adichie, C. N. 2019. O perigo de uma história única. Tradução de Júlia Romeu. 2. reimpressão. São Paulo: Companhia das Letras.

Alma no olho. 1973. [curta-metragem]. Direção e roteiro de Zózimo Bulbul. Brasil: [s. n.].

Almeida, R. 2017. Cinema e educação: fundamentos e perspectivas. Educação em Revista 33:e153836. DOI: https://doi.org/10.1590/0102-4698153836

Almeida, S. A. 2015. Etnossociolinguística e Letramentos: contribuições para um currículo bilíngue e intercultural indígena Apinajé. Tese de Doutorado, Universidade de Brasília, Departamento de Linguística, Brasília.

Bunzen, C. 2010. Os significados do letramento escolar como uma prática sociocultural, in Letramentos: rupturas, deslocamentos e repercussões de pesquisas em linguística aplicada. Organizado por C. Vóvio \& P. G. L. Sito, pp. 99-120. Campinas: Mercado de Letras.

Cafundó. 2005. [filme]. Dirigido por Paulo Betti e Clóvis Bueno. Brasil: LAZ Audiovisual/Prole de Adão Produções Artísticas.

Carvalho, N. S. 2013. Imagens do negro no cinema brasileiro - o período das Chanchadas. Cambiassu (12):81-94.

Carvalho, N. S., e P. Domingues. 2017. A representação do negro em dois manifestos do cinema brasileiro. Estudos Avançados 31(89):377-394. DOI: http://dx.doi.org/10.1590/s0103-40142017.31890027

Castilho, S. D. 2011. Quilombo contemporâneo: educação, família e culturas. Mato Grosso: EDUFMT.

Deleuze, G. 1985 Cinema: imagem-movimento. São Paulo: Brasiliense. 
Erickson, F. 1986. Qualitative methods in research on teaching, in Handbook of research on teaching. Editado por M. C. Wittrock, pp. 119-161. 3. ed. New York: Macmillan.

Erickson, F. 1988. Etnografia e educação: conceitos e uso. Tradução de Carmen Lúcia Guimarães de Mattos. Título original: Ethnographic Description no Sociolinguistics - An International Handbook of the Science of Language and Society. New York: Walter de Gruyter.

Freire, P. 1996. Pedagogia da autonomia: saberes necessários à prática educativa. 36. ed. São Paulo: Paz e Terra.

Gimeno Sacristán, J. 1999. Poderes instáveis em educação. Porto Alegre: Artmed.

Gomes, N. L. 2000. O impacto do diferente: reflexões sobre a escola e a diversidade cultural. Educação em Foco 4(4):21-27.

Lankshear, C., e M. Knobel. 2006. New literacies everyday practices and classroom learning. 2. ed. New York: Open University Press.

Lipovetsky, G., e J. Serroy. 2015. A estetização do mundo: viver na era do capitalismo artista. São Paulo: Companhia das Letras.

Maher, T. M. 2007. Do casulo ao movimento: a suspensão das certezas na educação bilíngue e intercultural, in Transculturalidade, linguagem e educação. Organizado por M. Cavalcanti \& S. M. Bertoni-Ricardi, pp. 67-96. Campinas: Mercado de Letras.

Mauss, M. 2003. Ensaio sobre a dádiva: forma e razão da troca nas sociedades arcaicas, in Sociologia e Antropologia, pp. 183-314. 1. ed. São Paulo: Cosaic Naify. Disponível em: https://repositorio.ufsc.br/ xmlui/handle/123456789/1888?show=full. Acesso em: 20 mar. 2020. 
Merleau-Ponty, M. 1994. Fenomenologia da percepção. Tradução de Carlos Alberto de Moura. São Paulo: Martins Fontes.

Miranda, D. S. 2019. Uma cinematografia dos minorizados, in Mostra Internacional do Cinema Negro. Organizado por C. L. Prudente, pp. 4-5. São Paulo. SESC.

Munanga, K. 1996. Origem e histórico do quilombo na África. Revista USP (28):56-63. DOI: https:// doi.org/10.11606/issn.2316-9036.v0i28p56-63

Nascimento, A. 1980. Quilombismo. Petrópolis: Vozes.

Passos, L. A., e C. L. Prudente. 2017. População em condição de rua: uma cultura da resistência contra a barbárie, in Relatório Estadual de direitos humanos e da terra 2017. Organizado por I. Werner et al., pp. 35-50. 1. ed. Cuiabá: Associação Antônio Vieira.

Périgo, A. 2018. Imagem de afirmação de professoras da educação básica: uma discussão mediada pela dimensão pedagógica do cinema negro. Dissertação de Mestrado Universidade Federal do Mato Grosso, Departamento de Educação, Cuiabá.

Picolli, L. 2010. Alfabetizações, alfabetismos e letramentos: trajetórias e conceitualizações. Educação \& Realidade 35(3):257-275.

Prudente, C. L. 1995. Barravento: o negro como possível referencial estético no cinema novo de Glauber Rocha. São Paulo: Editora Nacional.

Prudente, C. L. 2002. Mãos negras: antropologia da arte negra. São Paulo: Panorama.

Prudente, C. L. 2008. Cinema Negro: algumas contribuições reflexivas para a compreensão da questão afro-descendente na dinâmica sócio-cultural da imagem. São Paulo: Fiuza. 
Prudente, C. L., e R. S. P. Gilioli, 2013. Os povos bantos no Brasil. Mogi das Cruzes: Oriom.

Prudente, C. L. 2018. A dimensão pedagógica do cinema negro. AVANCA Cinema fournal 1:2-794.

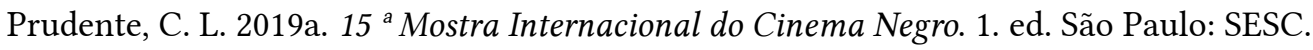

Prudente, C. L. 2019b. O tropicalismo como possível unidade estética da lusofonia de horizontalidade democrática: a dimensão pedagógica do cinema negro posta em questão, in $15{ }^{a}$ Mostra Internacional do Cinema Negro. Organizado por Celso Luiz Prudente, pp. 8-20. $1^{\text {a }}$. ed. São Paulo: SESC.

Prudente, C. L. 2019c. A dimensão pedagógica do Cinema Negro: a imagem de afirmação positiva do iberoásio-afro-ameríndio. Revista Extraprensa 13(1):6-25. DOI: https://doi.org/10.11606/extraprensa2019.163871

Prudente, C. L. 2019d. Étnico léxico: para compreensão da Prudentalidade, in A dimensão pedagógica do cinema negro aspectos de uma arte para a afirmação ontológica do negro brasileiro: o olhar de Celso Prudente. Organizado por C. L. Prudente e D. C. Silva, pp.171-177. 2. ed. São Paulo: Anita Garibaldi.

Prudente, C. L. 2019e. Políticas e gestão da educação superior, in As lutas de imagens das minorias versus a política da educação monocultural: as relações étnico-raciais postas em questão. Organizado por G. Tauchen \& A. G. Buza, v. 1, pp. 333-352. 1. ed. Curitiba: CRV.

Prudente, C. L., e D. C. Silva, 2019. A dimensão pedagógica do cinema negro: aspectos de uma arte para a afirmação ontológica do negro brasileiro: o olhar de Celso Prudente. 2. ed. São Paulo: Anita Garibaldi.

Quilombo. 1984. [filme]. Dirigido por C. Diegues. Produzido por Cacá Diegues e Augusto Arraes. Brasil: CDK/Embrafilme/Gaumont.

Rodas, J. G., e C. L. Prudente. 2009. Reflexões para o discernimento do estereótipo e a imagem do negro. Revista da Faculdade de Direito, Universidade de São Paulo 104: 499-506. 
Rodrigues, J. C. 1988. O negro brasileiro e o cinema. Rio de Janeiro: Pallas.

Salgado, A. C. P., e F. H. Dias. 2010. Desenvolver a Bilingualidade: foco da educação bilíngue e do ensino de línguas. Signo 35: 145-153.

Sartre, J.-P. 1960. Reflexões sobre o racismo. Tradutor J. Guinsburg. 2. ed. São Paulo: Ed. Difusão Europeia do Livro.

Silva, T. T. 2003. Documentos de identidade: uma introdução às teorias do currículo. 2. ed. Belo Horizonte: Autêntica.

Smolka, A. L. B. 2014. Verbete alfabetização como processo discursivo, in Glossário Ceale: termos de alfabetização, leitura e escrita para educadores. Organizado por I. C. A. S. Frade et al. Belo Horizonte: FaE UFMG. Disponível em: http://ceale.fae.ufmg.br/app/webroot/glossarioceale/verbetes/alfabetizacaocomo-processo-discursivo. Acesso em: 3 dez. 2019.

Soares, M. 2004. Letramento e alfabetização: as muitas facetas. Revista Brasileira de Educação(25):5-17. DOI: https://doi.org/10.1590/S1413-24782004000100002

Sousa, R. M. 2006. Gênero discursivo mediacional: uma pesquisa na perspectiva etnográfica. Tese de Doutorado, Universidade de Brasília, Departamento de Linguística, Brasília.

Spivak, G. C. 2010. Pode o subalterno falar?Tradução de S. R. G. Almeida et al. Belo Horizonte: Editora da UFMG.

Trevisan, D. 2019. Letramentos digitais críticos: habilidades mobilizadas por estudantes universitários em ambiente virtual de aprendizagem. Universidade Federal de Mato Grosso, Departamento de Educação, Cuiabá. 